\title{
A Smartphone Intervention for People With Serious Mental Illness: Fully Remote Randomized Controlled Trial of CORE
}

Dror Ben-Zeev ${ }^{1}$, PhD; Ayesha Chander ${ }^{1}$, MRes; Justin Tauscher ${ }^{1}$, PhD; Benjamin Buck ${ }^{1}$, PhD; Subigya Nepal ${ }^{2}$, BSc; Andrew Campbell ${ }^{2}, \mathrm{PhD}$; Guy Doron ${ }^{3}, \mathrm{PhD}$

\footnotetext{
${ }^{1}$ Behavioral Research in Technology and Engineering Center, Department of Psychiatry and Behavioral Sciences, University of Washington, Seattle, WA, United States

${ }^{2}$ Department of Computer Science, Dartmouth College, Hanover, NH, United States

${ }^{3}$ School of Psychology, Interdisciplinary Center, Herzliya, Israel
}

\section{Corresponding Author:}

Dror Ben-Zeev, PhD

Behavioral Research in Technology and Engineering Center

Department of Psychiatry and Behavioral Sciences

University of Washington

1959 NE Pacific Street

Seattle, WA, 98195

United States

Phone: 12066859655

Email: dbenzeev@uw.edu

\begin{abstract}
Background: People with serious mental illness (SMI) have significant unmet mental health needs. Development and testing of digital interventions that can alleviate the suffering of people with SMI is a public health priority.

Objective: The aim of this study is to conduct a fully remote randomized waitlist-controlled trial of CORE, a smartphone intervention that comprises daily exercises designed to promote reassessment of dysfunctional beliefs in multiple domains.

Methods: Individuals were recruited via the web using Google and Facebook advertisements. Enrolled participants were randomized into either active intervention or waitlist control groups. Participants completed the Beck Depression Inventory-Second Edition (BDI-II), Generalized Anxiety Disorder-7 (GAD-7), Hamilton Program for Schizophrenia Voices, Green Paranoid Thought Scale, Recovery Assessment Scale (RAS), Rosenberg Self-Esteem Scale (RSES), Friendship Scale, and Sheehan Disability Scale (SDS) at baseline (T1), 30-day (T2), and 60-day (T3) assessment points. Participants in the active group used CORE from T1 to $\mathrm{T} 2$, and participants in the waitlist group used CORE from T2 to T3. Both groups completed usability and accessibility measures after they concluded their intervention periods.
\end{abstract}

Results: Overall, 315 individuals from 45 states participated in this study. The sample comprised individuals with self-reported bipolar disorder $(111 / 315,35.2 \%)$, major depressive disorder $(136 / 315,43.2 \%)$, and schizophrenia or schizoaffective disorder $(68 / 315,21.6 \%)$ who displayed moderate to severe symptoms and disability levels at baseline. Participants rated CORE as highly usable and acceptable. Intent-to-treat analyses showed significant treatment $\times$ time interactions for the BDI-II $\left(F_{1,313}=13.38\right.$; $P<.001)$, GAD-7 $\left(F_{1,313}=5.87 ; P=.01\right)$, RAS $\left(F_{1,313}=23.42 ; P<.001\right)$, RSES $\left(F_{1,313}=19.28 ; P<.001\right)$, and SDS $\left(F_{1,313}=10.73\right.$; $P=.001)$. Large effects were observed for the BDI-II $(d=0.58)$, RAS $(d=0.61)$, and RSES $(d=0.64)$; a moderate effect size was observed for the SDS $(d=0.44)$, and a small effect size was observed for the GAD-7 $(d=0.20)$. Similar changes in outcome measures were later observed in the waitlist control group participants following crossover after they received CORE (T2 to T3). Approximately 41.5\% (64/154) of participants in the active group and 60.2\% (97/161) of participants in the waitlist group were retained at T2, and 33.1\% (51/154) of participants in the active group and 40.3\% (65/161) of participants in the waitlist group were retained at $\mathrm{T} 3$.

Conclusions: We successfully recruited, screened, randomized, treated, and assessed a geographically dispersed sample of participants with SMI entirely via the web, demonstrating that fully remote clinical trials are feasible in this population; however, study retention remains challenging. CORE showed promise as a usable, acceptable, and effective tool for reducing the severity of psychiatric symptoms and disability while improving recovery and self-esteem. Rapid adoption and real-world dissemination 
of evidence-based mobile health interventions such as CORE are needed if we are to shorten the science-to-service gap and address the significant unmet mental health needs of people with SMI during the COVID-19 pandemic and beyond.

Trial Registration: ClinicalTrials.gov NCT04068467; https://clinicaltrials.gov/ct2/show/NCT04068467

(J Med Internet Res 2021;23(11):e29201) doi: 10.2196/29201

\section{KEYWORDS}

mobile health; schizophrenia; bipolar disorder; depression; mobile phone

\section{Introduction}

\section{Background}

People with serious mental illnesses (SMIs), including schizophrenia-spectrum disorders, bipolar disorder, and severe and persistent depression, experience significant psychiatric symptoms such as hallucinations, delusions, and severe mood episodes. SMI is often accompanied by functional and psychosocial impairments, housing and employment challenges, and poverty [1-3]. Treatment of people with SMI typically takes place in publicly funded clinics and community mental health centers that are chronically underresourced, understaffed, and overextended [4,5]. These public sector agencies are rarely able to meet the demand for services [6]. Barriers in the capacity to provide high-quality care on the provider's side may be compounded by hesitancy around treatment seeking on the patient's side [7]. People with SMI are often exposed to pervasive societal stigma about their conditions and therefore can be reluctant to openly seek services at a clinic if it risks them being labeled mentally ill $[8,9]$. The consequence of these intersecting challenges is a vicious cycle in which those who are most impaired receive the least amount of support, thus deteriorating even more over time.

People with SMI are not dramatically different from the general population in their use of mobile technologies [10,11]. Owing to subsidy programs that offer people with disabilities access to mobile phones and data plans (eg, Federal Communications Commission Lifeline Program) and the dropping prices of mobile phones worldwide, people with SMI now have unprecedented opportunities to access information, stay connected to others, and potentially receive services remotely via personal mobile devices [12]. Survey studies conducted in recent years have shown that approximately two-thirds of people with SMI in the United States already own smartphones and that most are interested in leveraging them to support their health care [13-16]. Academic research groups and commercial companies are responding to the opportunity and have begun to develop and test a range of smartphone-supported digital health technologies for people with SMI, including illness self-management apps, virtual peer support platforms, and sensor-enabled remote patient monitoring systems [17-19].

Conducting the research necessary to demonstrate the safety and clinical utility of novel smartphone interventions for people with SMI is challenging and costly. Recruitment of participants for clinical trials is the most salient cause of study delays and a major obstacle in expeditiously moving novel and potentially helpful interventions to real-world practice [20]. Traditional participant recruitment strategies are dependent on collaborative partnerships with study sites and clinician referrals [21]. This creates potential biases in clinical trial samples, as the enrolled individuals already need to be known by health care providers and be actively receiving care to be offered the opportunity to engage in research. Therefore, the participant samples used in standard clinical trials may be particularly unrepresentative of hard-to-reach populations, such as people with SMI, who are known to disengage from clinic-based services for extended periods [22,23].

To overcome these obstacles, a growing number of studies have used web-based participant recruitment strategies, including social media advertisements, virtual outreach through web-based interest groups, search engine advertisements, and various other website campaigns. Across clinical populations, these efforts have yielded impressive results in terms of cost-effectiveness, time efficiency, and reach [24]. In clinical trials where the experimental intervention is digital and behavioral in nature (ie, does not require direct contact between a patient and a provider) and the comparator condition does not require in-person contact with the research team (eg, no intervention control, waitlist control, or digital attention-control alternative), recruitment, treatment, and assessment of outcomes can all be conducted fully remotely and potentially on a single device [25-30]. To our knowledge, fully remote randomized controlled trials have not been conducted with people with SMI [24].

\section{Objective}

Here, we report the first fully remote randomized controlled clinical trial of a mobile health (mHealth) intervention for people with SMI. The first objective of this study is to evaluate whether individuals with SMI can be successfully recruited, assessed, and engaged in a digital intervention in a fully remote clinical trial. The second objective of the study is to evaluate the clinical effectiveness of the CORE intervention, a smartphone app designed to challenge dysfunctional thoughts that underlie common symptoms of SMI, self-stigmatizing attitudes, and maladaptive beliefs that impede treatment seeking and recovery.

\section{Methods}

\section{Study Design}

This study involved a fully remote randomized controlled crossover waitlist trial design. All participants were given the opportunity to receive the study intervention. Following enrollment, participants were randomized to either receiving the CORE intervention (indicated as 1 ) or being in the waitlist control group (indicated as 0 ) in blocks of 4 . The group allocation for each block was selected randomly from a list of 6 possible sequences (ie, 1100, 1010, 1001, 0110, 0101, and 
0011). In the active intervention group, participants completed the baseline assessment and were then immediately given access to the CORE app for 30 days of use. After a month, they concluded the intervention, uninstalled the app, and completed a second assessment. After an additional month (at 60 days), they completed a third assessment to measure the stability of symptom change post intervention. In the control arm, participants waited 30 days to receive the CORE app. After a month, they completed a second assessment and were provided access to the CORE app. After an additional month (at 60 days), they completed a third assessment to measure within-subject changes.

\section{Procedures}

All study procedures were reviewed and approved by the institutional review board of the University of Washington (ID number 00006898). We put a detailed and institutional review board-approved plan in place to respond to cases of increased risk. Web-based recruitment was conducted through advertisements on Google and Facebook. Google advertisements are presented depending on the user's search terms. For this study, we selected a range of terms associated with severe mental illness (eg, schizophrenia, bipolar, seeing things, and am I crazy) and related keywords generated by the Google broad match algorithm. Facebook advertisements use a similar methodology to target individual interests. For this study, we targeted interests such as mental health and schizophrenia. Individuals who clicked on the advertisements were directed to the study website. The study website provided written and video descriptions of the project, a downloadable version of the study consent form, and an option to complete a screening questionnaire via a see if I am eligible button. If eligible, participants were again presented with the consent form and were required to answer questions demonstrating their understanding of the study details. If they answered these questions correctly within 3 attempts, they could proceed to the baseline assessments. Participants were excluded if they were unable to complete this step successfully, as they were deemed unable to provide informed consent. Participants completed a battery of self-report questionnaires on the web at baseline. If participants' responses to questionnaires indicated the presence of suicidal ideation, they were immediately provided with resources for emergency support. Upon completion of baseline questionnaires, participants were randomized to either an active intervention or waitlist control group. Those randomized to the active intervention arm were given instructions on how to download and install the CORE mobile app.

At the start of the study period, staff contacted participants via email or SMS text messaging to welcome them to the study and remind them to complete the follow-up assessments at 30 and 60 days. After this welcome message, participants interacted with the study team only if they reached out to the study staff for technical support. When participants were due for an assessment, they were sent an automated SMS text message to alert them to complete the battery through a weblink. Participants were incentivized by being entered into lotteries to win US \$500 and US \$1000 after completing the 30- and 60-day assessments, respectively.
A member (JT) of our research team who was blinded to participant allocation completed all study analyses, and these analyses were determined beforehand. All outcome measures were preselected by the study team and examined in this study. The sample size was calculated to fit analytic requirements, and study recruitment was discontinued once the required sample size was met.

\section{Participants}

Participants were eligible if they could speak English; were aged >18 years; lived in the United States; self-reported a diagnosis of schizophrenia or schizoaffective disorder, bipolar disorder, or major depressive disorder; and owned a smartphone with a data plan. They were excluded if they had previously participated in the study or were unavailable for 60 days of participation.

\section{Assessments}

At all assessments, we administered measures of depression (Beck Depression Inventory-II [BDI-II] [31]), anxiety (Generalized Anxiety Disorder-7 [GAD-7] [32]), auditory hallucinations (Hamilton Program for Schizophrenia Voices Questionnaire [HPSVQ] [33]), paranoid thinking (Green Paranoid Thoughts Scale [GPTS] [34]), recovery (Recovery Assessment Scale [RAS] [35,36]), self-esteem (Rosenberg Self-Esteem Scale [RSES] [37]), social isolation (The Friendship Scale [38]), and functional disability (Sheehan Disability Scale [SDS] [39]). At baseline, we collected information from participants regarding demographics and technology use. After the intervention period, participants also completed a 26-item self-report usability and acceptability measure comprising adapted items from the System Usability Scale [40], Post Study System Usability Questionnaire [40], Technology Assessment Model Measurement Scales [41], and Usefulness, Satisfaction, and Ease questionnaire [42]. Participants were asked to rate their agreement with a series of statements about the intervention. A similar measure was used in previous studies conducted by our group [43].

\section{Intervention Description}

The CORE intervention is a smartphone app that uses the GGtude platform, a system designed to increase the cognitive flexibility of individuals struggling with a range of mental health problems through brief daily training [44-47]. CORE was specifically designed to help counteract dysfunctional thoughts in multiple domains that are relevant to the subjective experience of having SMI. The intervention comprises daily brief game-like exercises designed to produce changes in the relative activation of adaptive and maladaptive beliefs about the self, others, and the world such that adaptive beliefs would be more easily retrieved than maladaptive ones.

CORE users were trained to respond to multiple statements in a sequence of modules that progress through the following domains: self-talk, belief in change, self-stigma, self-care, self-worth, illness and identity, personal strength, social avoidance, feelings versus facts, catastrophization, thoughts of reference, paranoid ideation (ie, people are against me), treatment seeking, and recovery. The modules begin with brief psychoeducation about the target domain and how maladaptive 
beliefs can hamper recovery. Thoughts appear as statements on the smartphone screen, and users are required to either endorse (ie, drag the statement down toward them on the touchscreen) or discard them (ie, push the statement upwards away from them). Users learn to embrace self-statements reflecting more nuanced adaptive thoughts (eg, belief in change, importance of self-care, alternative explanations to threat perceptions, and value of treatment seeking). The module content was organized into 53 levels, and participants were recommended to not complete more than 3 levels a day for a period of 30 days. Push notifications reminded users to complete their daily training. After each level, participants had the option of adding to their personal toolbox 1 of 3 positive statements that they most related to. Participants could access their toolbox at any time. Figure 1 depicts screenshots of the targeted beliefs menu, an example of a maladaptive statement, and a psychoeducational element.

Figure 1. Screenshots of the (a) targeted beliefs menu, (b) an example of a maladaptive statement, and (c) a psychoeducational element.

(a)

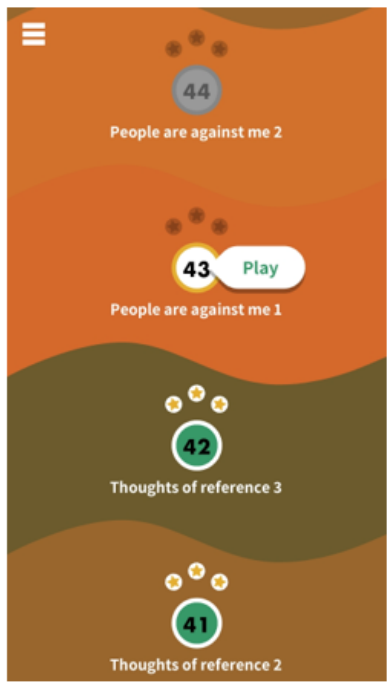

(b)

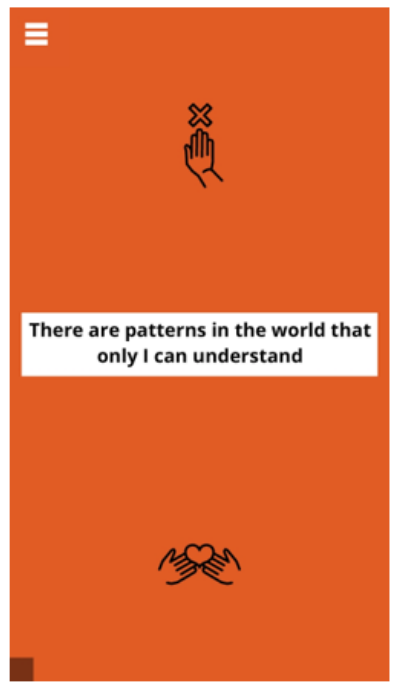

(c)

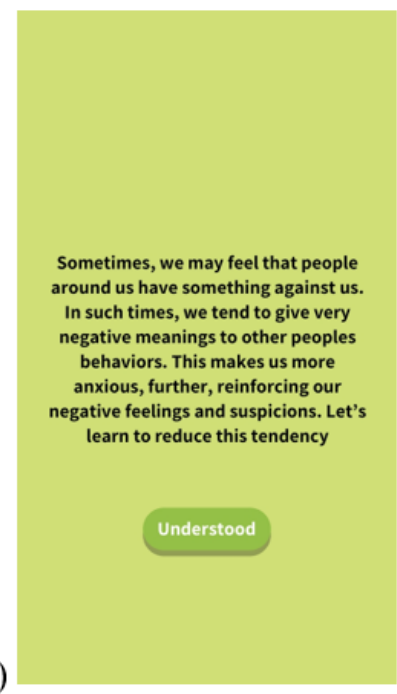

\section{Data Analysis}

Means, SDs, and frequencies were reported using descriptive statistics for all participant demographics, symptom measures, and acceptability and usability scale items. A series of $t$ tests and chi-square tests were used to test for group differences in demographic variables and symptom measures at baseline (T1) before examining intervention effects at 30 days (T2) and 60 days (T3). Pre- and postscores for both groups were explored using a series of repeated-measures analysis of variance (ANOVA). The intervention effect between groups at T2 was initially tested using a $2 \times 2$ mixed-design repeated-measures ANOVA, controlling for participant diagnosis and baseline assessment scores. A $1 \times 3$ repeated measures ANOVA tested the performance of the active group across $\mathrm{T} 1, \mathrm{~T} 2$, and $\mathrm{T} 3$, with post hoc Bonferroni pairwise comparisons used to explore outcomes when significant differences occurred. Finally, a series of $1 \times 3$ repeated measures ANOVAs tested the intervention effect after crossover (T2 and T3) for the waitlist control group participants to see if intervention effects were replicated. A series of equivalence tests were conducted using independent sample 2-tailed $t$ tests to determine whether the magnitude of intervention effects differed for the active group participants between $\mathrm{T} 1$ and $\mathrm{T} 2$ as compared with the intervention effect for waitlist control participants between T2 and T3. Spaghetti plots were provided to visualize changes over time across symptom measures in both groups. To minimize bias during analysis, we used an intent-to-treat approach and implemented a multiple imputation strategy to replace missing values [48]. Multiple imputation is considered the most appropriate method of handling missing data for a study of this size, has been used successfully in repeated measure designs, and has been shown to have utility with levels of missing data greater than that observed in this study [49,50]. Sensitivity analyses using pattern-mixture models were used to establish data that were missing at random before imputation [51]. Our imputation model was specified using data from participants in each condition and included participant demographic variables (ie, diagnosis, gender, age, and race) and all baseline assessment scores.

\section{Results}

\section{Recruitment and Enrollment}

Web-based recruitment advertisements were placed between January 2020 and September 2020, using a total budget of US $\$ 2984.26$. We recruited a total of 1123 people from these advertisements; of these 1123 people, 315 (28.04\%) were randomized for the trial, and $808(71.95 \%)$ were excluded. Of the 315 participants, $154(48.9 \%)$ dropped out of the study before $\mathrm{T} 2$ and $45(14.3 \%)$ dropped out between $\mathrm{T} 2$ and $\mathrm{T} 3$. Approximately $41.5 \%(64 / 154)$ of participants in the active group and $60.2 \%(97 / 161)$ of participants in the waitlist group were retained at $\mathrm{T} 2$, and $33.1 \%(51 / 154)$ of participants in the active group and $40.3 \%$ (65/161) of individuals in the waitlist group were retained at T3. Those who dropped out of the study were not found to differ significantly from those who were retained in terms of demographic characteristics or baseline scores on outcome measures (Figure 2). Most participants were recruited from Google advertisements (226/315, 71.7\%). Overall, Google advertisements were viewed 557,700 times 
and were ultimately clicked on 5100 times. The states with the most clicks on the Google advertisement were California (540/5100, 10.59\%), Texas $(393 / 5100,7.71 \%)$, Florida (295/5100, 5.78\%), and New York (294/5100, 5.77\%). The most successful Google advertisement keywords for increasing engagement from potential participants were mental health, mental illness, depression, illuminati, and bipolar. Most individuals $(4734 / 5100,92.82 \%)$ clicked on the advertisement through mobile phones, whereas few used desktop computers
$(256 / 5100,5.02 \%)$ or tablets $(110 / 5100,2.16 \%)$. Participants that enrolled in the study were recruited from 45 states (Figure $3)$, with the most participants coming from California (24/315, $7.6 \%)$, Texas $(21 / 315,6.7 \%)$, Florida $(17 / 315,5.4 \%)$, New York $(16 / 315,5.1 \%)$, Pennsylvania $(16 / 315,5.1 \%)$, and Washington $(16 / 315,5.1 \%)$. We successfully enrolled participants from $80 \%(12 / 15)$ of the most rural states in the country.

Figure 2. CONSORT (Consolidated Standards of Reporting Trials) diagram.

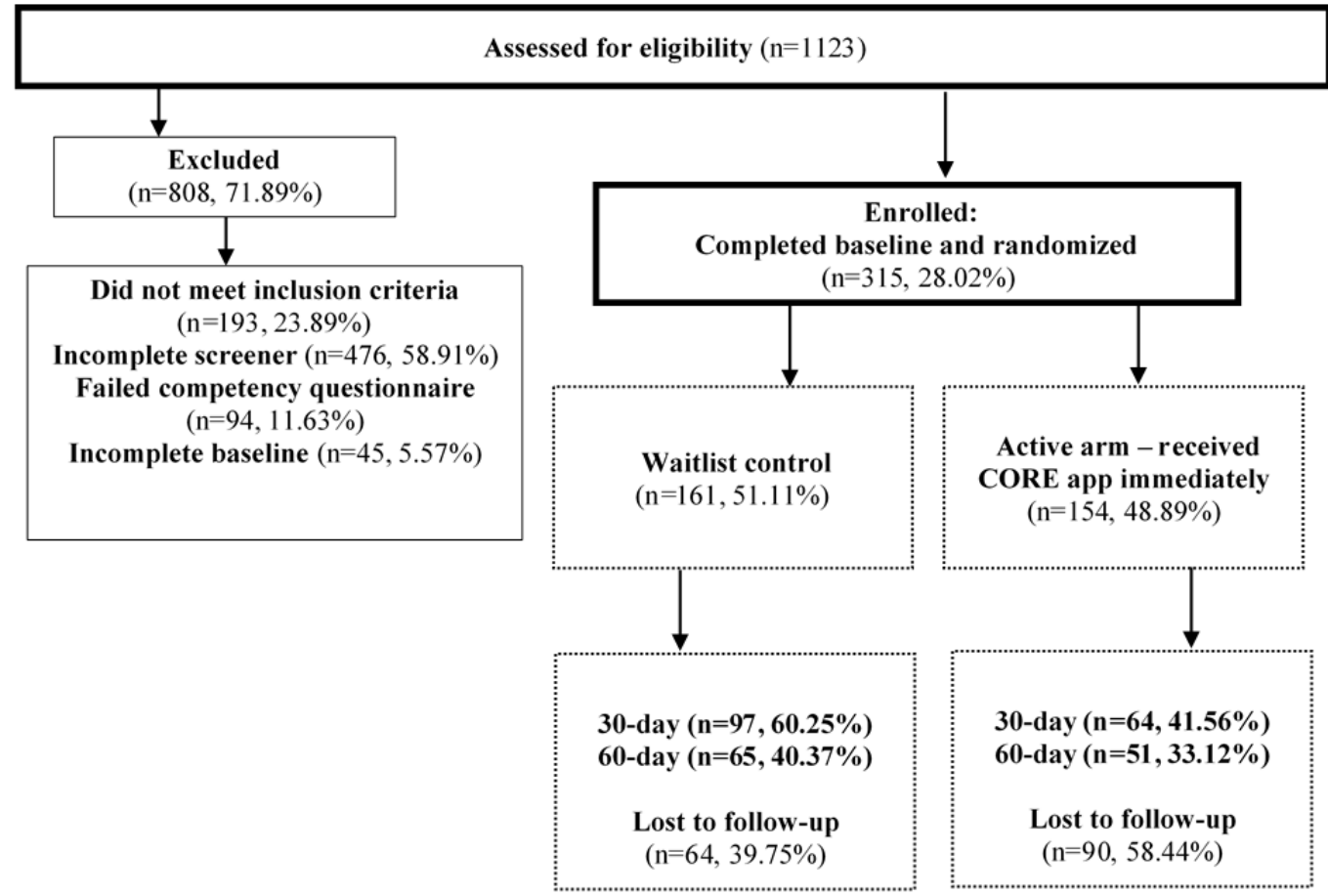

Figure 3. Map of participants enrolled based on location.

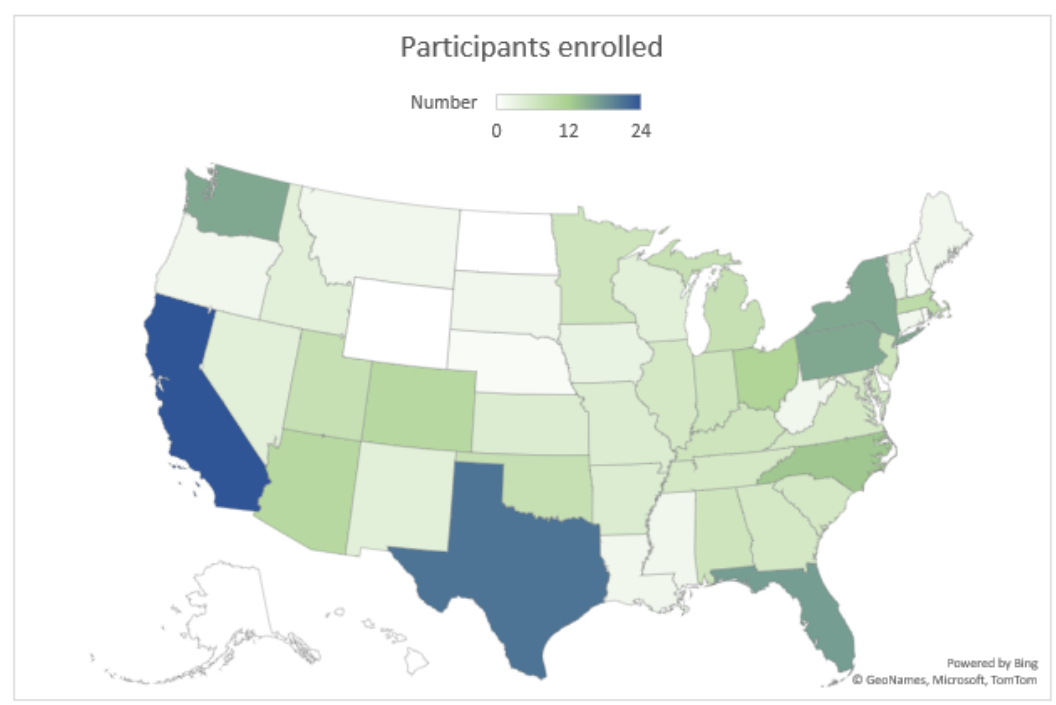

\section{Demographics}

Full demographics of the study participants are reported in Table 1. The final study participants were mostly female $(264 / 315$, $83.8 \%)$, White $(241 / 315,76.5 \%)$, heterosexual (218/315,
$69.2 \%)$, living independently $(150 / 315,47.6 \%)$ or with family $(136 / 315,43.2 \%)$, unemployed $(210 / 315,66.7 \%)$, and aged between 18-78 years. No demographic differences were observed following randomization between the 2 study groups. 
Table 1. Participant demographics and clinical history at baseline ( $\mathrm{N}=315)$.

\begin{tabular}{|c|c|c|}
\hline Characteristics & Waitlist $(\mathrm{n}=161)$ & Active $(n=154)$ \\
\hline Age (years), mean (SD) & $36.85(10.91)$ & $38.98(12.30)$ \\
\hline \multicolumn{3}{|l|}{ Gender, n (\%) } \\
\hline Female & $132(82)$ & $132(85.7)$ \\
\hline Male & $19(11.8)$ & $18(11.7)$ \\
\hline Transgender & $6(3.7)$ & 0 \\
\hline $\mathrm{MTF}^{\mathrm{a}}$ & $2(1.2)$ & 0 \\
\hline $\mathrm{FTM}^{\mathrm{b}}$ & $4(2.5)$ & $0(0)$ \\
\hline Nonbinary & $4(2.5)$ & $2(1.3)$ \\
\hline Other & 0 & $2(1.3)$ \\
\hline \multicolumn{3}{|l|}{ Diagnosis, $\mathbf{n}(\%)$} \\
\hline Bipolar disorder & $61(37.9)$ & $50(32.5)$ \\
\hline Major depressive disorder & $67(41.6)$ & $69(44.8)$ \\
\hline Schizophrenia or schizoaffective disorder & $33(20.5)$ & $35(22.7)$ \\
\hline \multicolumn{3}{|l|}{ Race, $n(\%)$} \\
\hline White & $118(73.3)$ & $123(79.9)$ \\
\hline Black or African American & $20(12.4)$ & $12(7.8)$ \\
\hline Asian & $6(3.7)$ & $4(2.6)$ \\
\hline Alaskan Native or American Indian & $1(0.6)$ & $1(0.6)$ \\
\hline Declined to answer & 0 & $1(0.6)$ \\
\hline More than one race & $16(9.9)$ & $13(8.4)$ \\
\hline \multicolumn{3}{|l|}{ Ethnicity, n (\%) } \\
\hline Spanish, Hispanic, or Latino & $17(10.6)$ & $13(8.4)$ \\
\hline Not Spanish, Hispanic, or Latino & $143(89.4)$ & $139(91.4)$ \\
\hline \multicolumn{3}{|l|}{ Education, n (\%) } \\
\hline Finished eighth grade & $3(1.9)$ & $1(0.7)$ \\
\hline Some high school & $10(6.2)$ & $5(3.3)$ \\
\hline High school diploma & $31(19.3)$ & $22(14.4)$ \\
\hline Some college or technical school & 47 (41.6) & $62(40.5)$ \\
\hline Associate's degree & $15(9.3)$ & $21(13.7)$ \\
\hline Bachelor's degree & $26(16.1)$ & $22(14.4)$ \\
\hline Some graduate school & $1(0.6)$ & $6(3.9)$ \\
\hline Master's degree & $7(4.3)$ & $13(8.5)$ \\
\hline Doctorate & $1(0.6)$ & $1(0.7)$ \\
\hline \multicolumn{3}{|l|}{ Employment status, n (\%) } \\
\hline Full-time & $23(14.3)$ & $29(19)$ \\
\hline Part-time & $27(16.8)$ & $17(11.1)$ \\
\hline Unemployed & $105(65.2)$ & $105(68.6)$ \\
\hline \multicolumn{3}{|l|}{ Living situation, n (\%) } \\
\hline Independent & $78(48.4)$ & $72(47.1)$ \\
\hline Living with family & $71(44.1)$ & $65(42.5)$ \\
\hline Homeless & $6(3.7)$ & $10(6.5)$ \\
\hline
\end{tabular}




\begin{tabular}{|c|c|c|}
\hline Characteristics & Waitlist $(\mathrm{n}=161)$ & Active $(n=154)$ \\
\hline Substance use treatment & 0 & $1(0.7)$ \\
\hline Assisted or supported living & $6(3.7)$ & $5(3.3)$ \\
\hline \multicolumn{3}{|l|}{ Lifetime psychiatric hospitalizations, n (\%) } \\
\hline 0 & $49(30.4)$ & $44(28.8)$ \\
\hline $1-5$ & $69(42.9)$ & $72(47.1)$ \\
\hline $6-10$ & $20(12.4)$ & $18(11.8)$ \\
\hline $11-15$ & $11(6.8)$ & $5(3.3)$ \\
\hline $16-20$ & $3(1.9)$ & $3(2)$ \\
\hline$>20$ & $9(5.6)$ & $11(7.2)$ \\
\hline \multicolumn{3}{|l|}{ Past-year psychiatric hospitalizations, n (\%) } \\
\hline 0 & $127(78.9)$ & $114(74.5)$ \\
\hline $1-5$ & $33(20.5)$ & $37(24.2)$ \\
\hline $6-10$ & $1(0.6)$ & $2(1.3)$ \\
\hline \multicolumn{3}{|l|}{ Frequency of auditory hallucinations, $n(\%)$} \\
\hline Never & $82(51.9)$ & $75(49)$ \\
\hline A few times a year & $24(15.2)$ & $23(15)$ \\
\hline Once or twice a month & $17(10.8)$ & $15(9.8)$ \\
\hline Once a week & $5(3.2)$ & $9(5.9)$ \\
\hline$\geq 2$ times a week & $30(19)$ & $31(20.3)$ \\
\hline Beck Depression Inventory-II, mean (SD) & $34.57(13.34)$ & $33.46(13.75)$ \\
\hline Green Paranoid Thought Scale, mean (SD) & $88.24(35.63)$ & $86.79(36.01)$ \\
\hline Hamilton Program for Schizophrenia Voices, mean (SD) & $19.86(9.03)$ & $18.42(8.81)$ \\
\hline Generalized Anxiety Disorder-7, mean (SD) & $13.89(5.77)$ & $14.42(5.16)$ \\
\hline Sheehan Disability Scale, mean (SD) & $24.11(7.21)$ & $24.11(7.02)$ \\
\hline
\end{tabular}

${ }^{\mathrm{a} M T F}$ : male-to-female.

${ }^{\mathrm{b}}$ FTM: female-to-male.

\section{Clinical Characteristics}

The sample comprised individuals with bipolar disorder $(111 / 315,35.2 \%)$, major depressive disorder $(136 / 315,43.2 \%)$, and schizophrenia or schizoaffective disorder $(68 / 315,21.6 \%)$. Approximately a quarter $(75 / 315,23.8 \%)$ of the participants reported experiencing auditory hallucinations on a weekly or more frequent basis at baseline. Approximately 23.2\% (73/315) of participants reported experiencing a psychiatric hospitalization in the past year, and $25.4 \%$ (80/315) of participants reported having $\geq 6$ psychiatric hospitalizations in their lifetime. Baseline scores on clinical outcome measures were in the severe range on both the BDI-II (mean 33.95, SD 13.61) and the GPTS (mean 87.51, SD 35.79) and in the moderate range on the GAD-7 (mean 14.12, SD 5.48) and HPSVQ (mean 19.08, SD 8.89). Participants had a moderate level of disability SDS (mean 24.07, SD 7.12). Significant correlations existed between scores on the BDI-II and GAD-7 $(r=0.69 ; P<.001)$, BDI-II and GPTS $(r=0.38 ; P<.001)$, and GAD-7 and GPTS $(r=0.40 ; P<.001)$, indicating a high degree of comorbidity within the sample. No differences were found between groups on any clinical characteristics or baseline outcome measures after randomization. Diagnosis was not found to be a significant predictor of completion at T2 or T3, with the distribution of completion resembling the distribution of participants at baseline. At T2, 20.5\% (33/161) of completers had a diagnosis of schizophrenia or schizoaffective disorder, $44.1 \%(71 / 161)$ had a diagnosis of major depressive disorder, and $35.4 \%$ (57/161) had a diagnosis of bipolar disorder. At T3, $23.3 \%$ (27/116) of completers had a diagnosis of schizophrenia or schizoaffective disorder, $46.6 \%(54 / 116)$ had a diagnosis of major depressive disorder, and 30.2\% (35/116) had a diagnosis of bipolar disorder.

\section{Engagement Metrics}

We were able to collect the CORE app use data from $51.4 \%$ $(162 / 315)$ of participants. Of the 162 participants, $82(50.6 \%)$ completed all 53 intervention levels, whereas participants, on average, completed 35 levels. Most participants reported that they would like to use CORE more often; that if they had access to CORE, they would use it; that the app was easy to use and sufficiently interactive; and that they did not need technical support to use CORE. Participants rated that they were satisfied with the CORE intervention and that they would recommend 
it to a friend. The distribution of participants' responses to all usability and acceptability questions is displayed in Table 2.

Table 2. Participant usability and acceptability ratings $(\mathrm{N}=119)$.

\begin{tabular}{|c|c|c|c|}
\hline Item & Disagree, n (\%) & Neutral, n (\%) & Agree, n (\%) \\
\hline I think that I would like to use CORE often. & $8(6.7)$ & $26(21.8)$ & $85(71.4)$ \\
\hline I thought CORE was easy to use. & $1(0.8)$ & $5(4.2)$ & $113(95.0)$ \\
\hline I found that the different parts of CORE work well together. & $1(0.8)$ & $23(19.3)$ & $95(79.8)$ \\
\hline I would imagine that most people would learn to use CORE very quickly. & $0(0.0)$ & $6(5.0)$ & $113(95.0)$ \\
\hline I felt very confident using CORE. & $1(0.8)$ & $24(20.2)$ & $94(79.0)$ \\
\hline Overall, I am satisfied with how easy it is to use CORE. & $1(0.8)$ & $8(6.7)$ & $110(92.4)$ \\
\hline I was able to use the modules quickly in CORE. & $3(2.5)$ & $8(6.7)$ & $108(90.8)$ \\
\hline I felt comfortable using CORE. & $0(0.0)$ & $9(7.6)$ & $110(92.4)$ \\
\hline It was easy to learn to use CORE. & $0(0.0)$ & $7(5.9)$ & $111(94.1)$ \\
\hline Whenever I made a mistake using CORE, I could recover easily and quickly. & $2(1.7)$ & $17(14.3)$ & $100(84.0)$ \\
\hline It was easy to find the information I needed. & $5(4.2)$ & $16(13.6)$ & $97(82.2)$ \\
\hline The information provided for CORE was easy to understand. & $2(1.7)$ & $10(8.5)$ & $105(89.7)$ \\
\hline How things appeared on the screen was clear. & $1(0.8)$ & $9(7.6)$ & $108(91.5)$ \\
\hline If I have access to CORE, I will use it. & $6(5.0)$ & $17(14.3)$ & $96(80.7)$ \\
\hline I am satisfied with CORE. & $7(5.9)$ & $11(9.2)$ & $101(84.9)$ \\
\hline I would recommend CORE to a friend. & $6(5.0)$ & $23(19.3)$ & $90(75.6)$ \\
\hline CORE is fun to use. & $7(5.9)$ & $44(37.0)$ & $68(57.1)$ \\
\hline CORE works the way I want it to work. & $10(8.4)$ & $28(23.5)$ & $81(68.1)$ \\
\hline I feel I need to have CORE. & $20(16.8)$ & $58(48.7)$ & $41(34.5)$ \\
\hline CORE helped me manage my symptoms. & $12(10.1)$ & $41(34.5)$ & $66(55.5)$ \\
\hline CORE was interactive enough. & $6(5.0)$ & $26(21.8)$ & $87(73.1)$ \\
\hline I found CORE to be very complicated & $108(90.8)$ & $7(5.9)$ & $4(3.4)$ \\
\hline I think that I would need the support of a technical person to be able to use CORE. & $103(86.6)$ & $7(5.9)$ & $9(7.6)$ \\
\hline I thought there was too much inconsistency in CORE. & $99(83.2)$ & $13(10.9)$ & $7(5.9)$ \\
\hline I found CORE very awkward to use. & $103(86.6)$ & $11(9.2)$ & $5(4.2)$ \\
\hline I needed to learn a lot of things before I could get going with CORE. & $105(88.2)$ & $8(6.7)$ & $6(5.0)$ \\
\hline
\end{tabular}

\section{Between-Group Differences: Active Group Versus Waitlist Control Group}

Analyses of differences between the active group and the waitlist control group from $\mathrm{T} 1$ to $\mathrm{T} 2$ revealed a significant treatment $\times$ time interaction effect for the BDI-II $\left(F_{1,313}=13.38\right.$; $P<.001)$, GAD-7 $\left(F_{1,313}=5.87 ; P=.02\right)$, RAS $\left(F_{1,313}=23.42\right.$; $P<.001)$, RSES $\left(F_{1,313}=19.28 ; P<.001\right)$, and SDS $\left(F_{1,313}=10.73\right.$; $P=.001)$. Large effects were observed at T2 for the BDI-II $(d=0.58), \operatorname{RAS}(d=0.61)$, and RSES $(d=0.64)$. A moderate effect was observed for the SDS $(d=0.44)$ and a small effect for the GAD-7 $(d=0.20)$.
This indicates that participants engaging in the active condition showed improvements on these outcome measures after 30 days of using the app compared with participants in the waitlist control group who did not have access to the app over the same period (Figure 4). A significant main effect of time was found for the BDI-II $\left(F_{1,313}=44.33 ; P<.001\right)$, GAD-7 $\left(F_{1,313}=66.77\right.$; $P<.001)$, GPTS $\left(F_{1,313}=39.85 ; P<.001\right)$, RAS $\left(F_{1,313}=46.15\right.$; $P<.001)$, RSES $\left(F_{1,313}=28.89 ; P<.001\right)$, Friendship Scale $\left(F_{1,313}=21.05 ; P<.001\right)$, and $\operatorname{SDS}\left(F_{1,313}=51.644 ; P<.001\right)$. Table 3 displays the means and SDs for all measures at each time point for the active group participants and the waitlist control group participants. 
Figure 4. Outcome measures (y-axis) at baseline (T1), 30 days (T2), and 60 days (T3) assessments points (x-axis) for active group and waitlist control group. BDI-II: Beck Depression Inventory-Second Edition; GAD-7: Generalized Anxiety Disorder-7; GPTS: Green Paranoid Thought Scale; HPSVQ: Hamilton Program for Schizophrenia Voices; RAS: Recovery Assessment Scale; RSES: Rosenberg Self-esteem Scale; SDS: Sheehan Disability Scale.
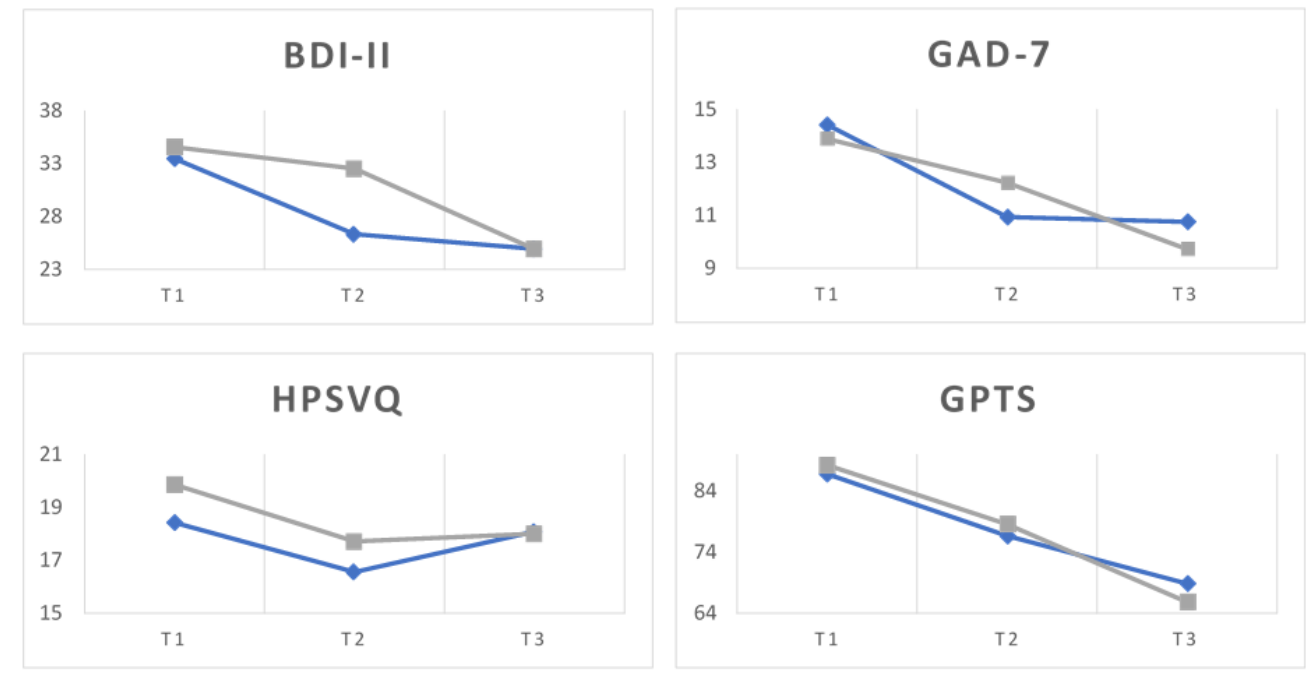

RAS
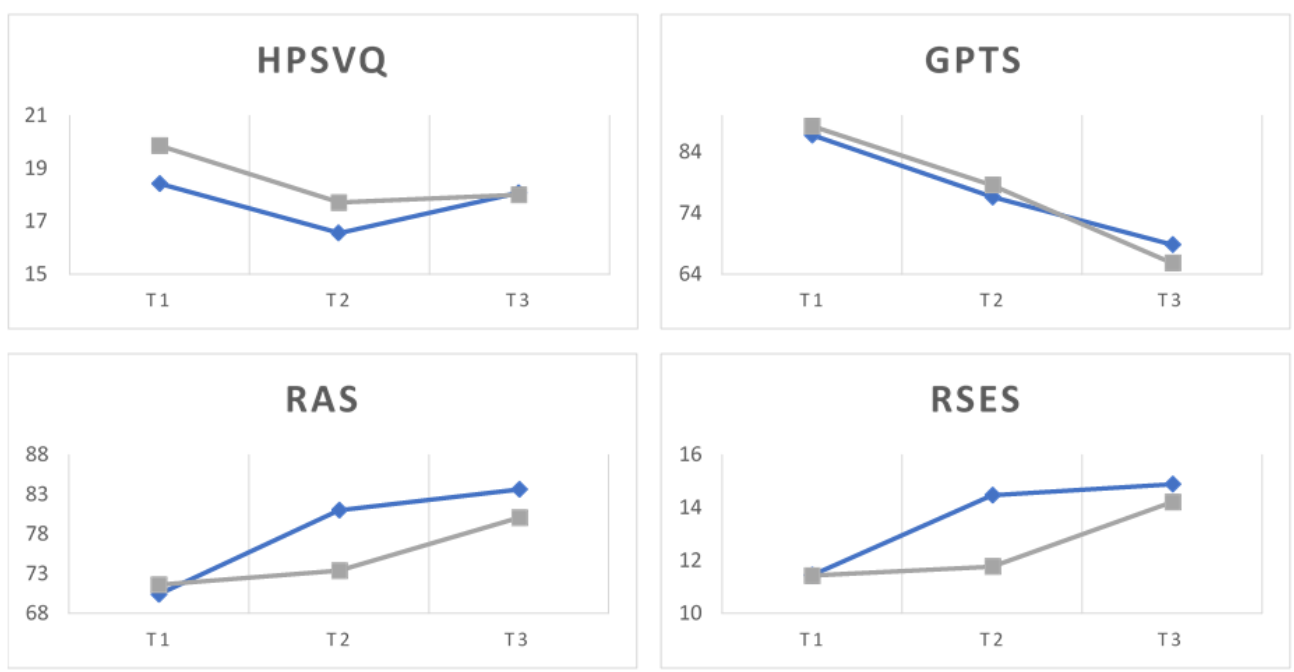

RSES

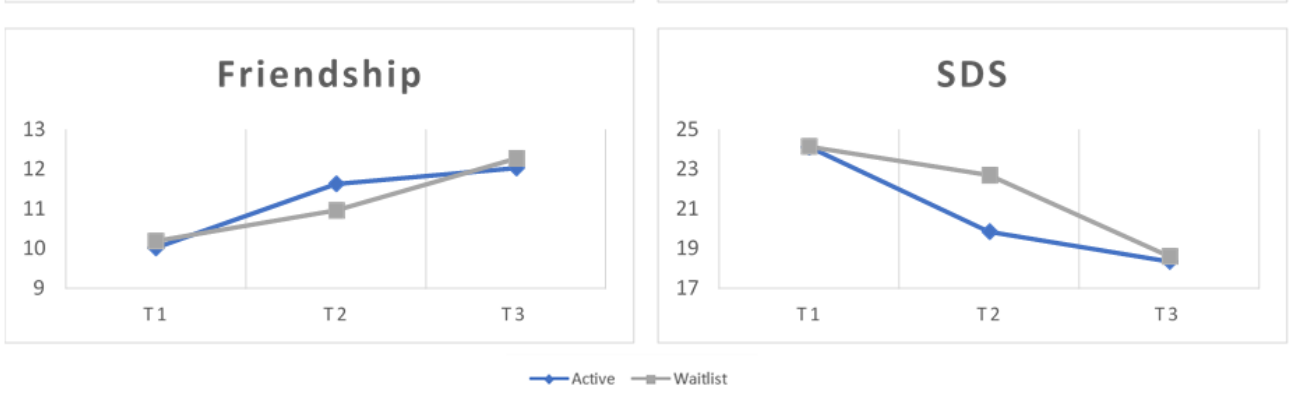


Table 3. Comparison of outcome measures across periods for each group.

\begin{tabular}{|c|c|c|c|}
\hline Measure & Baseline, mean (SD) & 30 days, mean $(\mathrm{SD})$ & 60 days, mean $(\mathrm{SD})$ \\
\hline \multicolumn{4}{|c|}{ Beck Depression Inventory-II } \\
\hline Active & $33.46(13.75)$ & $26.33(10.43)^{\mathrm{a}, \mathrm{b}}$ & $24.94(8.71)$ \\
\hline Waitlist & $34.57(13.34)$ & $32.52(11.12)$ & $24.93(10.59)^{b}$ \\
\hline \multicolumn{4}{|c|}{ Generalized Anxiety Disorder-7 } \\
\hline Active & $14.42(5.16)$ & $10.93(4.17)^{\mathrm{b}, \mathrm{c}}$ & $10.75(3.69)$ \\
\hline Waitlist & $13.89(5.77)$ & $12.23(5.00)^{\mathrm{d}}$ & $9.72(4.53)^{\mathrm{b}}$ \\
\hline \multicolumn{4}{|c|}{ Hamilton Program for Schizophrenia Voices Questionnaire } \\
\hline Active & $18.42(8.81)$ & $16.56(8.54)$ & $18.08(6.07)$ \\
\hline Waitlist & $19.86(9.03)$ & $17.71(10.20)$ & $18.00(11.99)$ \\
\hline \multicolumn{4}{|c|}{ Green Paranoid Thoughts Scale } \\
\hline Active & $86.79(36.01)$ & $76.66(23.97)^{\mathrm{b}}$ & $68.84(20.41)^{b}$ \\
\hline Waitlist & $88.24(35.63)$ & $78.59(27.54)^{b}$ & $65.84(24.11)^{\mathrm{b}}$ \\
\hline \multicolumn{4}{|c|}{ Recovery Assessment Scale } \\
\hline Active & $70.42(16.62)$ & $81.02(11.01)^{\mathrm{a}, \mathrm{b}}$ & $83.64(9.44)^{b}$ \\
\hline Waitlist & $71.61(17.18)$ & $73.38(12.44)$ & $80.06(13.08)^{\mathrm{b}}$ \\
\hline \multicolumn{4}{|c|}{ Rosenberg Self-Esteem Scale } \\
\hline Active & $11.45(6.39)$ & $14.47(4.28)^{\mathrm{a}, \mathrm{d}}$ & $14.89(4.28)$ \\
\hline Waitlist & $11.43(5.83)$ & $11.77(4.96)$ & $14.21(5.01)^{\mathrm{b}}$ \\
\hline \multicolumn{4}{|c|}{ Friendship scale } \\
\hline Active & $10.02(3.84)$ & $11.63(3.19)^{\mathrm{b}}$ & $12.03(3.00)$ \\
\hline Waitlist & $10.19(3.56)$ & $10.96(3.39)$ & $12.27(3.28)^{\mathrm{b}}$ \\
\hline \multicolumn{4}{|c|}{ Sheehan Disability Scale } \\
\hline Active & $24.12(7.03)$ & $19.85(6.26)^{\mathrm{b}, \mathrm{e}}$ & $18.35(6.38)^{\mathrm{d}}$ \\
\hline Waitlist & $24.14(7.21)$ & $22.70(5.83)^{\mathrm{d}}$ & $18.61(6.54)^{\mathrm{b}}$ \\
\hline
\end{tabular}

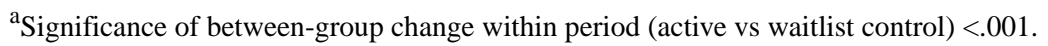

${ }^{\mathrm{b}}$ Significance of within-group change from the previous period $<.001$.

${ }^{\mathrm{c}}$ Significance of between-group change within period (active vs waitlist control) <.05.

${ }^{\mathrm{d}}$ Significance of within-group change from the previous period $<.01$.

${ }^{\mathrm{e}}$ Significance of between-group change within period (active vs waitlist control) <.01.

Within-Group Change: Active Intervention Group at T2 and Maintenance at T3

A series of $1 \times 3$ repeated-measures ANOVA was used to examine intervention effects within the active group between $\mathrm{T} 1$ and $\mathrm{T} 2$ and whether these effects were maintained 30 days after discontinuation of app use (Table 3). Results of the ANOVAs showed significant within-group differences for the BDI-II $\left(F_{2,306}=43.59 ; P<.001\right)$, GAD-7 $\left(F_{2,306}=43.71 ; P<.001\right)$, GPTS $\left(F_{2,306}=34.39 ; P<.001\right)$, RAS $\left(F_{2,306}=65.22 ; P<.001\right)$, $\operatorname{RSES}\left(F_{2,306}=32.85 ; P<.001\right)$, Friendship Scale $\left(F_{2,306}=17.94\right.$; $P<.001)$, and SDS $\left(F_{2,306}=56.21 ; P<.001\right)$. Large effect sizes were observed between $\mathrm{T} 1$ and $\mathrm{T} 2$ for the active intervention group on the BDI-II $(d=0.60)$, GAD-7 $(d=0.69), \operatorname{RAS}(d=0.70)$, and SDS $(d=0.63)$. Moderate to small effect sizes occurred during this period on the RSES $(d=0.47)$, GPTS $(d=0.35)$, and Friendship Scale $(d=0.39)$. No significant change was found at any time point for the active group for the HPSVQ $\left(F_{2}\right.$, ${ }_{306}=0.704 ; P=.51$ ). Bonferroni post hoc comparisons revealed significant improvements in each outcome measure at T2 except for the HPSVQ. All improvements were maintained between $\mathrm{T} 2$ and T3, with an additional small effect noted on the GPTS $(d=0.33)$, RAS $(d=0.27)$, and SDS $(d=0.24)$, suggesting a prolonged intervention effect. 
Within-Group Change: Waitlist Control Group at T2 and Following Crossover at T-3

Results from the active group were replicated following crossover in the waitlist control group between T2 and T3. Participants in the waitlist control group were found to have significant differences on the BDI-II $\left(F_{2,322}=60.79 ; P<.001\right)$, GAD-7 $\left(F_{2,322}=50.41 ; P<.001\right)$, GPTS $\left(F_{2,322}=55.15 ; P<.001\right)$, RAS $\left(F_{2,322}=32.03 ; P<.001\right)$, RSES $\left(F_{2,322}=34.35 ; P<.001\right)$, Friendship Scale $\left(F_{2,322}=26.28 ; P<.001\right)$, and $\operatorname{SDS}\left(F_{2}\right.$, $\left.{ }_{322}=50.93 ; P<.001\right)$. The lack of change in the HPSVQ scores after 30 days of CORE use was also replicated $\left(F_{2,322}=1.14\right.$; $P=.34)$. Post hoc analysis revealed that significant improvements took place for the waitlist control group between T2 and T3 for all outcome measures except HPSVQ. Effect size magnitudes were similar to those seen in the active group during the previous period, with large to moderate effects on the BDI-II $(d=0.73)$, GAD-7 $(d=0.46)$, GPTS $(d=0.48)$, RAS $(d=0.55)$, RSES $(d=0.52)$, Friendship Scale $(d=0.43)$, and SDS $(d=0.67)$. Improvements in the waitlist control group were also found between T1 and T2 for GAD-7, GPTS, and SDS. These improvements as a result of time were sufficient to negate a between-subject effect for the GPTS but not for the BDI-II or the GAD-7. The magnitude of change observed after 30 days of CORE use between groups was equivalent across all outcome metrics except for the RAS $\left(\mathrm{t}_{105}=2.28 ; P=.03\right)$, with the active group showing a slightly larger improvement than the waitlist control group.

\section{Discussion}

\section{Principal Findings}

Recent studies have demonstrated the feasibility of conducting remote trials of digital health apps for common mental health problems, including stress, anxiety, and depression [27-29]. This paper reports on the first fully remote randomized controlled trial of a smartphone intervention involving people with more severe forms of psychopathology, including schizophrenia and bipolar disorder. Building on and expanding web-based enrollment strategies used in previous works [52,53], we were able to reach, recruit, randomize, treat, and assess a sociodemographically diverse sample of participants from 45 states, far exceeding the reach of traditional localized study recruitment approaches and at a fraction of the cost. A key advantage of remote research strategies leveraging web-based recruitment advertisements lies in the flexibility they afford the investigative team to determine the geographical regions and roll out of study recruitment materials. Similar to what has been shown with other clinical populations [24], this proved to be a remarkably efficient methodology of reaching people with SMI who are more impaired and often considered more complex to engage in research [54].

This study found that a novel smartphone app, CORE, proved to be usable, acceptable, and effective in improving recovery and reducing the severity of psychiatric symptoms among individuals with SMI. Our findings align with an ample body of digital mental health research suggesting that mHealth smartphone apps can be of clinical value to people with SMI
$[17,55,56]$. Integration of technology with human support can bolster the engagement and clinical potency of technology-based treatments for SMI $[57,58]$. The CORE intervention was entirely self-navigated by users in the study who received minimal or no remote technical support from our study staff. We are not advocating for a shift toward fully automated approaches as the preferred model. However, what this study did demonstrate is that when technology is designed with the characteristics of the intended users in mind (ie, in terms of functionality, accessibility, navigability, and content), deployment of specialty digital mental health tools that do not involve humans in the loop of care can also produce significant clinical benefits.

The CORE intervention builds on a digital cognitive training strategy that has been previously demonstrated to reduce dysfunctional self-talk and increase resilience in community-based subclinical groups [44-46]. The app included modules focused on countering maladaptive beliefs in common mental health domains (eg, self-esteem, distinguishing thoughts from feelings, social anxiety, and catastrophizing) as well as modules specifically designed for people with SMI (eg, stigma related to mental illness, threat perception and persecutory ideation, hopelessness, strengths-based recovery, self-care, and treatment seeking). Thus, it is meant to be used transdiagnostically [59].

Although this study was a fully remote trial that relied entirely on participants' self-reports, we are confident that we were able to reach our intended target audience; most of our study sample reported having a psychiatric diagnosis of schizophrenia, schizoaffective disorder, or bipolar disorder; a history of multiple psychiatric hospitalizations; and being unemployed. Approximately one-tenth reported being currently homeless or residing in an assisted-living facility. Combined with the sample's average baseline ratings showing moderate to severe psychiatric symptom severity and moderate to high levels of disability, our data suggest that the sample comprised people with significant functional impairment.

The waitlist-controlled study design enabled the evaluation of both between-group effects during the intervention period and within-group changes in both groups over time. The results demonstrated a link between the timing of participants' exposure to the treatment app and when they experienced significant changes in key clinical and functional measures. A combination of factors such as simplicity, brevity, daily use, and game-like interactions may have encouraged the use of the CORE app. Daily practice comprising identification and categorization of self-statements, repeated exposure to adaptive self-statements, and psychoeducation may have facilitated retrieval of adaptive beliefs over maladaptive ones, thereby reducing the severity of symptoms [60]

This study has several limitations. The opportunity to participate was available only to individuals who used the internet (ie, to receive study recruitment advertisements) and who owned smartphones (ie, to download the CORE app) and therefore may not be representative of the full range of people with SMI. Similar to fully remote digital mental health trials involving participants with less severe psychopathology [61], our study sample was overrepresented by female participants $(264 / 315$, 
$83.8 \%$ ), and study dropout rates were high, requiring significant data imputation. All screening and assessment questions relied on individuals' self-reports but were not corroborated by a trained clinician or additional documentation (eg, EHR data). Replication of our findings in samples that were screened, diagnosed, and assessed by trained clinical assessors could bolster confidence in the nature of our results. Using a waitlist control is often considered a more ethical study design than offering no treatment at all or sham interventions. However, it may also have artificially inflated estimates of the intervention effects; asking participants who are ready for treatment to wait to receive CORE may have frustrated them, stalled their attempts to make independent changes, or artificially delayed their seeking other treatment options. Finally, although our measure of recovery taps willingness to ask for help [35,36], we did not formally evaluate changes in treatment-seeking behavior, which is an area of focus in the CORE training program and the key variable of interest.

\section{Conclusions}

Mental health researchers, funders, industry leaders, patients, and their caregivers have been advocating for the development and deployment of effective digital health tools to improve the outcomes of people with psychiatric conditions [62,63]. The global COVID-19 pandemic has led to major disruptions in the delivery of standard mental health services and has shed light on the vulnerabilities intrinsic to complete reliance on clinic-based treatment models [64,65]. In the context of this ongoing public health crisis, new scientific evidence showing that remotely-accessed mHealth technologies such as CORE can be navigable and beneficial to people with SMI is very encouraging. Regulatory bodies have taken active steps to remove barriers to the use of digital health technologies for psychiatric disorders [66]. Currently, rapid adoption and real-world dissemination of evidence-based digital health interventions are needed if we are to shorten the science-to-service gap and help address the significant unmet mental health needs of people with SMI during the pandemic and beyond.

\section{Acknowledgments}

The authors DBZ, AC, JT, SN, and AC were supported by an award from National Institute of Mental Health (NIMH) (R01MH112641). BB was supported by a Mentored Patient-Oriented Research Career Development Award from NIMH (K23MH122504).

\section{Conflicts of Interest}

DBZ has an intervention content licensing agreement with Pear Therapeutics and has a financial interest in Merlin LLC and FOCUS technology. He has consulted with Trusst Health, K Health, eQuility, and Otsuka Pharmaceuticals Ltd. GD is the cofounder of GGtude Ltd and has a financial interest in the CORE app described in this paper. Data analyses were conducted by members of the team who were unaffiliated with GGtude Ltd. All the remaining authors have no conflicts of interest to declare.

\section{Multimedia Appendix 1}

CONSORT-eHEALTH (V 1.6.1).

[PDF File (Adobe PDF File), 370 KB-Multimedia Appendix 1]

\section{References}

1. Harvey PD, Heaton RK, Carpenter WT, Green MF, Gold JM, Schoenbaum M. Functional impairment in people with schizophrenia: focus on employability and eligibility for disability compensation. Schizophr Res 2012 Sep;140(1-3):1-8 [FREE Full text] [doi: 10.1016/j.schres.2012.03.025] [Medline: 22503642]

2. Folsom DP, Hawthorne W, Lindamer L, Gilmer T, Bailey A, Golshan S, et al. Prevalence and risk factors for homelessness and utilization of mental health services among 10,340 patients with serious mental illness in a large public mental health system. Am J Psychiatry 2005 Feb;162(2):370-376. [doi: 10.1176/appi.ajp.162.2.370] [Medline: 15677603]

3. Sylvestre J, Notten G, Kerman N, Polillo A, Czechowki K. Poverty and serious mental illness: toward action on a seemingly intractable problem. Am J Community Psychol 2018 Mar;61(1-2):153-165. [doi: 10.1002/ajcp.12211] [Medline: 29243829]

4. Rosenblatt RA, Andrilla CH, Curtin T, Hart LG. Shortages of medical personnel at community health centers: implications for planned expansion. JAMA 2006 Mar 01;295(9):1042-1049. [doi: 10.1001/jama.295.9.1042] [Medline: 16507805]

5. Rosenberg S, Rosenberg J. Community Mental Health: Challenges for the 21st Century. New York: Routledge; 2017.

6. Mojtabai R, Fochtmann L, Chang S, Kotov R, Craig TJ, Bromet E. Unmet need for mental health care in schizophrenia: an overview of literature and new data from a first-admission study. Schizophr Bull 2009 Jul;35(4):679-695 [FREE Full text] [doi: 10.1093/schbul/sbp045] [Medline: 19505994]

7. Mojtabai R, Olfson M, Sampson NA, Jin R, Druss B, Wang PS, et al. Barriers to mental health treatment: results from the National Comorbidity Survey Replication. Psychol Med 2011 Aug;41(8):1751-1761 [FREE Full text] [doi:

10.1017/S0033291710002291] [Medline: 21134315]

8. Ben-Zeev D, Young MA, Corrigan PW. DSM-V and the stigma of mental illness. J Ment Health 2010 Aug;19(4):318-327. [doi: 10.3109/09638237.2010.492484] [Medline: 20636112] 
9. Corrigan PW, Druss BG, Perlick DA. The impact of mental illness stigma on seeking and participating in mental health care. Psychol Sci Public Interest 2014 Oct;15(2):37-70. [doi: 10.1177/1529100614531398] [Medline: 26171956]

10. Firth J, Cotter J, Torous J, Bucci S, Firth JA, Yung AR. Mobile phone ownership and endorsement of "mHealth" among people with psychosis: a meta-analysis of cross-sectional studies. Schizophr Bull 2016 Mar;42(2):448-455 [FREE Full text] [doi: 10.1093/schbul/sbv132] [Medline: 26400871]

11. Ben-Zeev D, Davis KE, Kaiser S, Krzsos I, Drake RE. Mobile technologies among people with serious mental illness: opportunities for future services. Adm Policy Ment Health 2013 Jul;40(4):340-343 [FREE Full text] [doi: 10.1007/s10488-012-0424-x] [Medline: 22648635]

12. Ben-Zeev D. Mobile health for all: public-private partnerships can create a new mental health landscape. JMIR Ment Health 2016 Jun 06;3(2):e26 [FREE Full text] [doi: 10.2196/mental.5843] [Medline: 27268283]

13. Aschbrenner KA, Naslund JA, Grinley T, Bienvenida JC, Bartels SJ, Brunette M. A survey of online and mobile technology use at peer support agencies. Psychiatr Q 2018 Sep;89(3):539-548 [FREE Full text] [doi: 10.1007/s11126-017-9561-4] [Medline: 29302771]

14. Brunette MF, Achtyes E, Pratt S, Stilwell K, Opperman M, Guarino S, et al. Use of smartphones, computers and social media among people with SMI: opportunity for intervention. Community Ment Health J 2019 Aug;55(6):973-978 [FREE Full text] [doi: 10.1007/s10597-019-00431-7] [Medline: 31175518 ]

15. Young AS, Cohen AN, Niv N, Nowlin-Finch N, Oberman RS, Olmos-Ochoa TT, et al. Mobile phone and smartphone use by people with serious mental illness. Psychiatr Serv 2020 Mar 01;71(3):280-283 [FREE Full text] [doi: 10.1176/appi.ps.201900203] [Medline: 31744429]

16. Noel VA, Acquilano SC, Carpenter-Song E, Drake RE. Use of mobile and computer devices to support recovery in people with serious mental illness: survey study. JMIR Ment Health 2019 Feb 20;6(2):e12255 [FREE Full text] [doi: 10.2196/12255] [Medline: 30785401$]$

17. Nicholas J, Larsen ME, Proudfoot J, Christensen H. Mobile apps for bipolar disorder: a systematic review of features and content quality. J Med Internet Res 2015 Aug 17;17(8):e198 [FREE Full text] [doi: 10.2196/jmir.4581] [Medline: 26283290]

18. Camacho E, Levin L, Torous J. Smartphone apps to support coordinated specialty care for prodromal and early course schizophrenia disorders: systematic review. J Med Internet Res 2019 Nov 12;21(11):e16393 [FREE Full text] [doi: 10.2196/16393] [Medline: $\underline{31714250]}$

19. Fortuna KL, Naslund JA, LaCroix JM, Bianco CL, Brooks JM, Zisman-Ilani Y, et al. Digital peer support mental health interventions for people with a lived experience of a serious mental illness: systematic review. JMIR Ment Health 2020 Apr 03;7(4):e16460 [FREE Full text] [doi: 10.2196/16460] [Medline: 32243256]

20. Gul RB, Ali PA. Clinical trials: the challenge of recruitment and retention of participants. J Clin Nurs 2010 Jan;19(1-2):227-233. [doi: 10.1111/j.1365-2702.2009.03041.x] [Medline: 20500260]

21. Caldwell PH, Hamilton S, Tan A, Craig JC. Strategies for increasing recruitment to randomised controlled trials: systematic review. PLoS Med 2010 Nov 09;7(11):e1000368 [FREE Full text] [doi: 10.1371/journal.pmed.1000368] [Medline: 21085696]

22. Kreyenbuhl J, Nossel IR, Dixon LB. Disengagement from mental health treatment among individuals with schizophrenia and strategies for facilitating connections to care: a review of the literature. Schizophr Bull 2009 Jul;35(4):696-703 [FREE Full text] [doi: 10.1093/schbul/sbp046] [Medline: 19491314]

23. Smith TE, Easter A, Pollock M, Pope LG, Wisdom JP. Disengagement from care: perspectives of individuals with serious mental illness and of service providers. Psychiatr Serv 2013 Aug 01;64(8):770-775. [doi: 10.1176/appi.ps.201200394] [Medline: 23632442]

24. Brøgger-Mikkelsen M, Ali Z, Zibert JR, Andersen AD, Thomsen SF. Online patient recruitment in clinical trials: systematic review and meta-analysis. J Med Internet Res 2020 Nov 04;22(11):e22179 [FREE Full text] [doi: 10.2196/22179] [Medline: 33146627]

25. Irvine AB, Gelatt VA, Seeley JR, Macfarlane P, Gau JM. Web-based intervention to promote physical activity by sedentary older adults: randomized controlled trial. J Med Internet Res 2013 Feb 05;15(2):e19 [FREE Full text] [doi: 10.2196/jmir.2158] [Medline: 23470322]

26. Clarke J, Sanatkar S, Baldwin PA, Fletcher S, Gunn J, Wilhelm K, et al. A web-based cognitive behavior therapy intervention to improve social and occupational functioning in adults with type 2 diabetes (The SpringboarD Trial): randomized controlled trial. J Med Internet Res 2019 May 21;21(5):e12246 [FREE Full text] [doi: 10.2196/12246] [Medline: 31115345]

27. Pratap A, Renn BN, Volponi J, Mooney SD, Gazzaley A, Arean PA, et al. Using mobile apps to assess and treat depression in Hispanic and Latino populations: fully remote randomized clinical trial. J Med Internet Res 2018 Aug 09;20(8):e10130 [FREE Full text] [doi: 10.2196/10130] [Medline: 30093372]

28. Arean PA, Hallgren KA, Jordan JT, Gazzaley A, Atkins DC, Heagerty PJ, et al. The use and effectiveness of mobile apps for depression: results from a fully remote clinical trial. J Med Internet Res 2016 Dec 20;18(12):e330 [FREE Full text] [doi: 10.2196/jmir.6482] [Medline: 27998876]

29. Moberg C, Niles A, Beermann D. Guided self-help works: randomized waitlist controlled trial of Pacifica, a mobile app integrating cognitive behavioral therapy and mindfulness for stress, anxiety, and depression. J Med Internet Res 2019 Jun 08;21(6):e12556 [FREE Full text] [doi: 10.2196/12556] [Medline: 31199319] 
30. Anguera JA, Jordan JT, Castaneda D, Gazzaley A, Areán PA. Conducting a fully mobile and randomised clinical trial for depression: access, engagement and expense. BMJ Innov 2016 Jan;2(1):14-21 [FREE Full text] [doi: 10.1136/bmjinnov-2015-000098] [Medline: 27019745]

31. Beck AT, Steer RA, Brown GK. Manual for the Beck Depression Inventory-II. San Antonio, TX: Psychological Corporation; 1996.

32. Spitzer RL, Kroenke K, Williams JB, Löwe B. A brief measure for assessing generalized anxiety disorder: the GAD-7. Arch Intern Med 2006 May 22;166(10):1092-1097. [doi: 10.1001/archinte.166.10.1092] [Medline: 16717171]

33. Van Lieshout RJ, Goldberg JO. Quantifying self-reports of auditory verbal hallucinations in persons with psychosis. Can J Behav Sci/ Revue canadienne des sciences du comportement 2007;39(1):73-77. [doi: 10.1037/cjbs2007006]

34. Green CE, Freeman D, Kuipers E, Bebbington P, Fowler D, Dunn G, et al. Measuring ideas of persecution and social reference: the Green et al. Paranoid Thought Scales (GPTS). Psychol Med 2008 Jan;38(1):101-111. [doi: 10.1017/S0033291707001638] [Medline: 17903336]

35. Salzer MS, Brusilovskiy E. Advancing recovery science: reliability and validity properties of the Recovery Assessment Scale. Psychiatr Serv 2014 Apr 01;65(4):442-453. [doi: 10.1176/appi.ps.201300089] [Medline: 24487405]

36. Corrigan PW, Salzer M, Ralph RO, Sangster Y, Keck L. Examining the factor structure of the recovery assessment scale. Schizophr Bull 2004;30(4):1035-1041. [doi: 10.1093/oxfordjournals.schbul.a007118] [Medline: 15957202]

37. Rosenberg M. Society and the Adolescent Self-Image. Princeton, NJ: Princeton University Press; 2015.

38. Hawthorne G, Griffith P. The Friendship Scale: Development and Properties. Melbourne: Centre for Program Evaluation; 2000 .

39. Sheehan DV. The Anxiety Disease. New York: Scribner; 1983.

40. Lewis J. Psychometric evaluation of the PSSUQ using data from five years of usability studies. Int J Human Comput Interac 2002 Sep;14(3-4):463-488. [doi: 10.1080/10447318.2002.9669130]

41. Venkatesh V, Davis FD. A theoretical extension of the technology acceptance model: four longitudinal field studies. Manag Sci 2000 Feb;46(2):186-204. [doi: 10.1287/mnsc.46.2.186.11926]

42. Lund A. Measuring usability with the USE questionnaire. Usablity Interf 2001;8(2):3-6. [doi: 10.1177/1078087402250360]

43. Ben-Zeev D, Brenner CJ, Begale M, Duffecy J, Mohr DC, Mueser KT. Feasibility, acceptability, and preliminary efficacy of a smartphone intervention for schizophrenia. Schizophr Bull 2014 Nov;40(6):1244-1253 [FREE Full text] [doi: 10.1093/schbul/sbu033] [Medline: 24609454]

44. Aboody D, Siev J, Doron G. Building resilience to body image triggers using brief cognitive training on a mobile application: a randomized controlled trial. Behav Res Ther 2020 Nov;134:103723. [doi: 10.1016/j.brat.2020.103723] [Medline: 32920164]

45. Cerea S, Ghisi M, Bottesi G, Carraro E, Broggio D, Doron G. Reaching reliable change using short, daily, cognitive training exercises delivered on a mobile application: the case of Relationship Obsessive Compulsive Disorder (ROCD) symptoms and cognitions in a subclinical cohort. J Affect Disord 2020 Nov 01;276:775-787. [doi: 10.1016/j.jad.2020.07.043] [Medline: 32738662]

46. Roncero M, Belloch A, Doron G. Can brief, daily training using a mobile app help change maladaptive beliefs? Crossover randomized controlled trial. JMIR Mhealth Uhealth 2019 Feb 13;7(2):e11443 [FREE Full text] [doi: 10.2196/11443] [Medline: 30758294]

47. Giraldo-O'Meara M, Doron G. Can self-esteem be improved using short daily training on mobile applications? Examining real world data of GG Self-esteem users. Clin Psychol 2021 May 17:131-139. [doi: 10.1111/cp.12219]

48. Gupta SK. Intention-to-treat concept: a review. Perspect Clin Res 2011 Jul;2(3):109-112 [FREE Full text] [doi: 10.4103/2229-3485.83221] [Medline: 21897887]

49. Cheema JR. Some general guidelines for choosing missing data handling methods in educational research. J Mod App Stat Meth 2014 Nov 01;13(2):53-75. [doi: 10.22237/jmasm/1414814520]

50. Vallejo G, Fernández MP, Livacic-Rojas PE, Tuero-Herrero E. Comparison of modern methods for analyzing repeated measures data with missing values. Multivariate Behav Res 2011 Nov 30;46(6):900-937. [doi: 10.1080/00273171.2011.625320] [Medline: 26736117]

51. Little RJ. Pattern-mixture models for multivariate incomplete data. J Am Stat Assoc 1993 Mar 20;88(421):125-134. [doi: 10.2307/2290705]

52. Crosier BS, Brian RM, Ben-Zeev D. Using Facebook to reach people who experience auditory hallucinations. J Med Internet Res 2016 Jun 14;18(6):e160 [FREE Full text] [doi: 10.2196/jmir.5420] [Medline: 27302017]

53. Ben-Zeev D, Buck B, Chander A, Brian R, Wang W, Atkins D, et al. Mobile RDoC: using smartphones to understand the relationship between auditory verbal hallucinations and need for care. Schizophr Bull Open 2020 Nov 9;1(1):sgaa060 [FREE Full text] [doi: 10.1093/schizbullopen/sgaa060] [Medline: 33937774]

54. Ben-Zeev D, Atkins DC. Bringing digital mental health to where it is needed most. Nat Hum Behav 2017 Dec;1(12):849-851. [doi: 10.1038/s41562-017-0232-0] [Medline: 31024173]

55. Bell IH, Lim MH, Rossell SL, Thomas N. Ecological momentary assessment and intervention in the treatment of psychotic disorders: a systematic review. Psychiatr Serv 2017 Nov 01;68(11):1172-1181. [doi: 10.1176/appi.ps.201600523] [Medline: 28669284] 
56. Depp CA, Moore RC, Perivoliotis D, Granholm E. Technology to assess and support self-management in serious mental illness. Dialogues Clin Neurosci 2016 Jun;18(2):171-183 [FREE Full text] [Medline: 27489457]

57. Noel VA, Carpenter-Song E, Acquilano SC, Torous J, Drake RE. The technology specialist: a 21st century support role in clinical care. NPJ Digit Med 2019 Jun 26;2:61 [FREE Full text] [doi: 10.1038/s41746-019-0137-6] [Medline: 31388565]

58. Jonathan GK, Pivaral L, Ben-Zeev D. Augmenting mHealth with human support: notes from community care of people with serious mental illnesses. Psychiatr Rehabil J 2017 Sep;40(3):336-338 [FREE Full text] [doi: 10.1037/prj0000275] [Medline: 28891660]

59. Ben-Zeev D, Buck B, Chu PV, Razzano L, Pashka N, Hallgren KA. Transdiagnostic mobile health: smartphone intervention reduces depressive symptoms in people with mood and psychotic disorders. JMIR Ment Health 2019 Apr 12;6(4):e13202 [FREE Full text] [doi: 10.2196/13202] [Medline: 30977736]

60. Brewin CR. Understanding cognitive behaviour therapy: a retrieval competition account. Behav Res Ther 2006 Jun;44(6):765-784. [doi: 10.1016/j.brat.2006.02.005] [Medline: 16620779]

61. Arean PA, Hallgren KA, Jordan JT, Gazzaley A, Atkins DC, Heagerty PJ, et al. The use and effectiveness of mobile apps for depression: results from a fully remote clinical trial. J Med Internet Res 2016 Dec 20;18(12):e330 [FREE Full text] [doi: 10.2196/jmir.6482] [Medline: 27998876]

62. Mohr DC, Azocar F, Bertagnolli A, Choudhury T, Chrisp P, Frank R, Banbury Forum on Digital Mental Health. Banbury forum consensus statement on the path forward for digital mental health treatment. Psychiatr Serv 2021 Jun;72(6):677-683. [doi: 10.1176/appi.ps.202000561] [Medline: 33467872]

63. Opportunities and challenges of developing information technologies on behavioral and social science clinical research. National Institute of Mental Health. 2018. URL: https://www.nimh.nih.gov/about/advisory-boards-and-groups/namhe/ reports/bsscr-ops-dd-final 155109.pdf [accessed 2021-10-21]

64. Ben-Zeev D. The digital mental health genie is out of the bottle. Psychiatr Serv 2020 Dec 01;71(12):1212-1213. [doi: 10.1176/appi.ps.202000306] [Medline: 32576123]

65. Torous J, Jän Myrick K, Rauseo-Ricupero N, Firth J. Digital mental health and COVID-19: using technology today to accelerate the curve on access and quality tomorrow. JMIR Ment Health 2020 Mar 26;7(3):e18848 [FREE Full text] [doi: 10.2196/18848] [Medline: $\underline{32213476]}$

66. Enforcement policy for digital health devices for treating psychiatric disorders during the coronavirus disease 2019 (COVID-19) public health emergency. U.S Food \& Drug Administration. 2020. URL: https://www.fda.gov/ regulatory-information/search-fda-guidance-documents/ enforcement-policy-digital-health-devices-treating-psychiatric-disorders-during-coronavirus-disease [accessed 2021-10-20]

\author{
Abbreviations \\ ANOVA: analysis of variance \\ BDI-II: Beck Depression Inventory-Second Edition \\ GAD-7: Generalized Anxiety Disorder-7 \\ GPTS: Green Paranoid Thought Scale \\ HPSVQ: Hamilton Program for Schizophrenia Voices \\ mHealth: mobile health \\ RAS: Recovery Assessment Scale \\ RSES: Rosenberg Self-Esteem Scale \\ SDS: Sheehan Disability Scale \\ SMI: Serious Mental Illness
}

Edited by R Kukafka, G Eysenbach; submitted 30.03.21; peer-reviewed by A Bourla, I Bell, Z Ali, M Toenning; comments to author 10.05.21; revised version received 19.05.21; accepted 03.10.21; published 12.11.21

Please cite as:

Ben-Zeev D, Chander A, Tauscher J, Buck B, Nepal S, Campbell A, Doron G

A Smartphone Intervention for People With Serious Mental Illness: Fully Remote Randomized Controlled Trial of CORE

J Med Internet Res 2021;23(11):e29201

URL: https://www.jmir.org/2021/11/e29201

doi: $10.2196 / 29201$

PMID:

CDror Ben-Zeev, Ayesha Chander, Justin Tauscher, Benjamin Buck, Subigya Nepal, Andrew Campbell, Guy Doron. Originally published in the Journal of Medical Internet Research (https://www.jmir.org), 12.11.2021. This is an open-access article distributed 
under the terms of the Creative Commons Attribution License (https://creativecommons.org/licenses/by/4.0/), which permits unrestricted use, distribution, and reproduction in any medium, provided the original work, first published in the Journal of Medical Internet Research, is properly cited. The complete bibliographic information, a link to the original publication on https://www.jmir.org/, as well as this copyright and license information must be included. 